\title{
STRATEGI PENINGKATAN DAYA SAING INDUSTRI PERKAPALAN ( SHIPBUILDING INDUSTRY)
}

SHIP INDUSTRY COMPETITIVENESS STRATEGY (SHIPBUILDING INDUSTRY)

\author{
Aziz Ikhsan Bachtiar")1, Marimin*), Luky Adrianto*), dan Romie Oktovianus Bura*) \\ *) Sekolah Bisnis, IPB University \\ Jl. Raya Pajajaran, Bogor, Indonesia 16151 \\ *) Departemen Teknologi Industri Pertanian, Fakultas Teknologi Pertanian, IPB University \\ Gedung Fateta Lantai 2, Kampus IPB Dramaga, Bogor, Indonesia \\ *) Departemen Manajemen Sumberdaya Perairan, Fakultas Perikanan dan Ilmu Kelautan, IPB University \\ Jl. Agatis, Kampus IPB Darmaga Bogor \\ **) Departemen Teknologi Pertahanan, Fakultas Teknologi Pertahanan, Universitas Pertahanan \\ Komplek Indonesia Peace and Security Center (IPSC) Sentul Bogor Jawa Barat
}

\begin{abstract}
The shipping industry is one of the industries that can advance global economic integration. Currently, the commercial shipbuilding sector is dominated by China, Japan, Korea, and European countries. The domestic shipping supporting industry has not met all the needs of domestic ships, both warships and commercial ships, and ships used for domestic shipping are almost entirely purchases of used vessels from abroad because they are cheap. In contrast, the contribution of the domestic industry only accounts for less than $10 \%$. This research aimed to formulate a development strategy for the shipping industry by increasing competitiveness to support maritime policies and fulfill the needs of the TNI's Alutsista. This study used the Analytical Network Process (ANP) method. The results showed that the priority strategies that could be implemented comprise seven clusters: Supporting industries (share technology development), core industries (technological capabilities), engineering specifications and designs (idea), feasibility studies (technological readiness), research and development (technological innovation), factor conditions (human resources), and government (long-term program). There are different priority strategies in each cluster.
\end{abstract}

Keywords: analytical network process (anp), competitiveness, shipbuilding industry

\begin{abstract}
Abstrak: Industri perkapalan merupakan salah satu industri yang dapat memajukan integrasi ekonomi global. Saat ini sektor pembuatan kapal komersial telah didominasi oleh Cina, Jepang, Korea, dan negara-negara Eropa. Permasalahan yang dihadapi industri perkapalan Indonesia saat ini adalah industri pendukung perkapalan dalam negeri belum mampu memenuhi seluruh kebutuhan kapal dalam negeri baik kapal perang maupun kapal komersial, dan kapal yang digunakan untuk pelayaran domestik hampir seluruhnya merupakan pembelian kapal bekas dari luar negeri karena harganya murah sedangkan kontribusi industri dalam negeri hanya mencapai kurang dari 10\% (Kemenko Maritim, 2017). Tujuan dari penelitian ini adalah bertujuan merumuskan strategi pembangunan industri perkapalan dengan menaikkan daya saing dalam rangka mendukung kebijakan kelautan dan pemenuhan kebutuan Alutsista TNI. Penelitian ini menggunakan metode Analytical Network Process (ANP). Hasil analisis menunjukkan strategi prioritas yang dapat diterapkan terdiri dari tujuh cluster diantaranya industri pendukung (share technology development), industri inti (technological capabilities), rekayasa spesifikasi dan desain (idea), study kelayakan (technological readiness), penelitan dan pengembangan (technological innovation), faktor kondisi (human resources), dan pemerintah (program jangka panjang). Pada masing-masing cluster terdapat strategi prioritas yang berbedabeda.
\end{abstract}

Kata kunci: analytical network process (anp), daya saing, industri perkapalan

\footnotetext{
${ }^{1}$ Alamat Korespondensi:

Email: aziz64ib@gmail.com
} 


\section{PENDAHULUAN}

Indonesia memiliki potensi kelautan yang besar, baik dalam sumber daya yang terkandung di dalamnya maupun ekonomi yang dapat ditingkatkan dengan pemanfaatan yang efektif dan efisien. Pemerintah telah mengeluarkan beberapa upaya untuk menjadikan Indonesia sebagai poros maritim dunia dengan mengeluarkan Peraturan Presiden Nomor 16 Tahun 2017 Tentang Kebijakan Kelautan Indonesia. Namun beberapa kebijakan ini belum mampu mencapai visi Indonesia sebagai negara maritim. Selain itu, Alat utama sistem senjata (Alutsista) TNI dapat dipenuhi jika industri maritim salah satunya industri perkapalan dapat menguasai teknologi pembuatan kapal. Oleh karena itu, analisis kemampuan daya saing dan penguatan perusahaan galangan kapal nasional harus dilihat dari konteks persaingan pasar global, khususnya galangan kapal kelas menengah ke atas, karena potensi pasar lokal juga merupakan bagian dari pasar global (Ma'ruf, 2007).

Industri pembangunan kapal merupakan salah satu industri yang dapat memajukan integrasi ekonomi global melalui suatu interaksi kekuatan ekonomi, sosial, klimatologis dan teknis, membawa lautan ke garis depan pengembangan sumber daya dan aktivitas bisnis. Saat ini sektor pembuatan kapal komersial telah didominasi oleh Cina, Jepang, Korea, dan Negara-negara Eropa, sedangkan sektor pembuatan kapal perang didominasi oleh Amerika Serikat, Cina, EC, Rusia, Jepang, dan India. Sedangkan industri pembuatan kapal selalu didominasi oleh negara-negara maritim seperti Inggris, Prancis, Jerman, Amerika Serikat, Jepang, Korea, dan Cina. Pembuatan kapal memiliki dua segmen utama yaitu segmen kapal komersial dan segmen kapal perang.

Menurut Lloyd's List Intelligence (2018) pengiriman kapal baru mengalami pertumbuhan sebesar 3,5\% sampai lima tahun kedepan. Seperti yang terlihat pada Gambar 1 mengenai pertumbuhan total permintaan kapal global dalam satuan Compesated Gross Tonnage (CGT) mengalami penurunan di tahun 2018.

Diperkirakan bahwa negara-negara Amerika Utara akan mendapatkan pangsa pasar sebesar $41,9 \%$ dan negara-negara di Asia Pasific sebesar 26,2\% serta negara-negara Eropa sebesar 22,2\%, Timur Tengah juga berkontribusi sebesar 5,5\%. Pesanan kapal perang jenis
Fregate menjadi yang terbesar sesuai dengan kebutuhan pertahanan masing-masing negara karena kemampuan tempurnya yang fleksibel, dapat bertempur di perairan dalam dan di wilayah perairan dangkal dengan pangsa pasar sebesar $28,7 \%$.

Pada tahun 2017 tercatat bahwa industri galangan kapal dalam negeri memiliki sekitar 250 unit, di mana 179 unit di antaranya mampu membangun kapal baru dengan total kapasitas terpasang $936.000 \mathrm{dwt}$ (deadweight tons) atau 624.000 GT (gross tons) per tahun (Ma'ruf, 2014). Galangan-galangan tersebut umumnya berukuran kecil, yang tersebar di seluruh Indonesia. Namun dari keseluruhan jumlah tersebut, hanya 25 unit berkapasitas 5.001-50.000 dwt, termasuk empat galangan BUMN, yaitu: PT PAL Indonesia, PT Dok dan Perkapalan Kodja Bahari (DKB), PT Dok dan Perkapalan Surabaya (DPS), dan PT Industri Kapal Indonesia.

Menurut EU-Indonesia Business Network (2013) untuk pembuatan kapal komersial galangan kapal di Indonesia sudah dapat melaksanakan desain dan rekayasa termasuk pembuatan kontruksi bangunan kapal. Akan tetapi, untuk material masih 65\% diimpor dari luar negeri dan $35 \%$ didukung dari dalam negeri. Ini menunjukkan industri pendukung dalam negeri belum mampu memenuhi kebutuhan peralatan mesin dan elektronik kapal. Disamping itu kapasitas galangan juga masih terbatas sampai dengan 50.000 DWT, sehingga untuk kapal dengan tonase diatas 50.000 DWT didukung dari pengadaan luar negeri.

Rendahnya tingkat produktivitas galangan kapal nasional disebabkan terbatasnya kapasitas dan fasilitasnya, serta peralatan-peralatan produksinya umumnya sudah tua dan berteknologi konvensional. Hal ini yang membuat tahapan teknologi produksinya sulit ditingkatkan (Ma'ruf, 2014). Rata-rata pembangunan kapal di galangan nasional masih lama sehingga membuat sulit bersaing. Untuk kapal tanker $6.500 \mathrm{dwt}$ misalnya, 2 galangan asing di Batam menawarkan ratarata 4 hingga 7 bulan lebih cepat daripada 3 galangan nasional, bahkan Jepang menawarkan separuh waktu yang ditawarkan Indonesia dengan harga hanya 10\% lebih mahal. Tongkang 300 feet dan kapal tunda 2.400 HP, galangan di Batam menawarkan waktu 20 hingga $25 \%$ lebih cepat, dan harga 8 hingga 10\% lebih murah daripada harga penawaran galangan kapal nasional (Ma'ruf, 2014). 


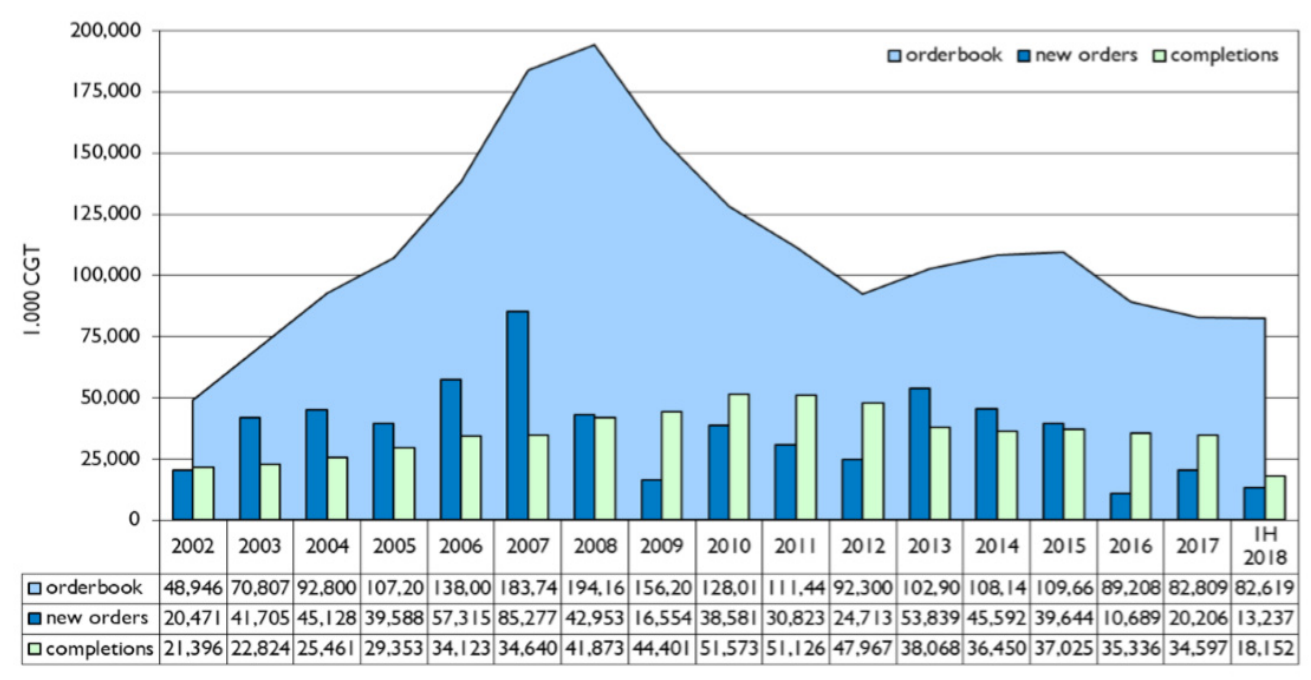

Gambar 1. Produksi kapal global dengan satuan CGT (Sea Europe, 2018)

Pada pengembangan industri perkapalan dalam negeri, dibutuhkan pendekatan secara ekonomi yang lebih komprehensif termasuk pembentukan cluster, pelaksanaan program alih teknologi dan analisis daya saing industri . Menurut Marčeta dan Bojnec (2020) daya saing global negara-negara EU-28 dapat ditingkatkan dengan pengembangan cluster yang tersebar luas dan mendorong inovasi dan bisnis lainnya di pasar internasional. Amdam dan Bjarnar (2015) menjelaskan kombinasi persaingan dan kerja sama, termasuk berbagi pengetahuan antar perusahaan, merupakan mekanisme yang penting dan berkontribusi pada daya saing cluster.

Cluster terdiri dari beberapa industri terkait dan perusahaan lain yang penting bagi persaingan perusahaan termasuk pemasok input khusus seperti komponen, mesin dan layanan, dan menyediakan infrastruktur khusus (Porter, 1998). Dan menurut Sarturi (2016) cluster yang terkonsentrasi secara geografik memiliki daya saing yang lebih baik. Čolović (2016), Stichhauerova (2020) mengatakan cluster berdampak positive terhadap industri dan dapat mempercepat pertumbuhan dan pengembangan teknologi. Fongsuwan (2017) dalam penelitiannya menemukan bahwa cluster tetap menjadi faktor penting untuk penelitian dan Pengembangan baik di dalam maupun di luar organisasi agar dapat bersaing dengan negara asing, dan untuk menciptakan keunggulan kompetitif dengan menekankan pada biaya, kualitas, dan pengiriman tepat waktu. Menurut Gajsek dan Kovac (2016), cluster telah dikembangkan untuk mencapai keunggulan kompetitif, efisiensi yang lebih tinggi, inovasi, produktivitas dan mempercepat komersialisasi .
Diamond Model dengan perspektif strategi dikembangkan oleh Porter (1990) merupakan metode yang sangat baik untuk mengetahui daya saing negara. Menurut Tu (2011) aspek kerjasama dan persaingan di dalam cluster industri dapat menciptakan keuntungan daya saing. Hal ini diperjelas lagi oleh Wahad (2017) bahwa cluster dapat menciptakan daya saing pada perusahaan kecil dan menengah dan dapat memperbaiki daya saing perusahaan pada jangka panjang. Porter (1990) menilai bahwa perusahaan secara nyata tidak hanya bersaing dengan perusahaan yang ada dalam industri saat ini. Namun, dikatakan pula bahwa perusahaan juga bersaing dengan pesaing potensial nya, yaitu mereka yang akan masuk, pemasok atau suplier, pembeli atau konsumen, dan produsen produkproduk pengganti yang tergambar dalam five forces model. Untuk mendukung industri perkapalan agar menjadi lebih maju, peran pemerintah dalam model Porter dijelaskan dapat dilakukan salah satunya dengan memberikan keringanan pajak dan kemudahan akses modal. Seperti yang dijelaskan oleh Arshad (2020) menyatakan bahwa pemerintah merupakan faktor kunci terhadap pengembangan industri.

Sementara terkait dengan transfer teknologi, menurut Gross (2012) dan Cunningham (2016) Alih Teknologi (AT) berkaitan dengan membawa teknologi dari sumber inovasi ke pasar dan universitas memainkan peran dalam memfasilitasi trasnformasi teknologi dari kegiatan penelitian murni hingga komersialisasi. Lee dan Ngo (2012) menyebutkan bahwa indikator Triple Helix membantu mempelajari sejauh mana jaringan hubungan antara universitas, industri, dan pemerintah telah berkembang menjadi konfigurasi sinergis. Sedangkan kendala bagi negara berkembang 
untuk melaksanakan AT adalah mahalnya biaya yang dibutuhkan dalam mentransfer teknologi (Kominfo, 2015). Menurut Hassan (2015) faktor yang paling berpengaruh dalam transfer teknologi adalah penyedia teknologi dan karakteristik penerima teknologi, integrasi aktor lokal dan asing, kebijakan pemerintah, perbedaan budaya, lingkungan transfer, sifat teknologi, mode transfer, dan manajemen program alih teknologi. Alih teknologi penting untuk dilaksanakan karena pemenuhan kebutuhan pasar ditentukan oleh kualitas teknologi dan dominasi componen utama pada produk yang dihasilkan (Wang, 2016).

Penelitian ini bertujuan untuk merumuskan strategi pembangunan industri perkapalan dengan menaikkan daya saing dalam rangka mendukung kebijakan kelautan dan pemenuhan kebutuan alutsista TNI. Penelitian ini juga diharapkan dapat memberikan sumbangan pemikiran bagi pembangunan industri perkapalan Indonesia dan dijadikan penerapan strategi dalam rangka meningkatkan daya saing industri perkapalan.

\section{METODE PENELITIAN}

Penelitian dilakukan di Jakarta, Batam, dan Surabaya yang menjadi lokasi industri perkapalan berada termasuk lembaga pendidikan, laboratorium, dan institusi TNI AL sebagai pengguna kapal perang. Data primer dikumpulkan melalui melalui Focus Group Discussion (FGD) dan wawancara mendalam terhadap 13 pakar di Surabaya pada 11 Maret 2020, khususnya pejabat/praktisi dalam kelembagaan pertahanan dan para peneliti/pengambil kebijakan khususnya yang berakitan dengan pembangunan industri maritim untuk mendukung kebijakan kelautan Indonesia dan Pemenuhan Kebutuhan Alutsisa TNI AL. Kuesioner ANP juga diberikan kepada pelaku dalam industri pertahanan yaitu TNI AL Mabes TNI dan Kementerian Pertahanan dan juga kepada lembaga penelitian seperti Lembaga Hidrografi Indonesia, BPPT (Badan Pengkajian Pembangunan Teknologi). Sampel ditentukan secara purposive sampling.

Penelitian ini menggunakan alat analisis analytical network process (ANP). Menurut Saaty dan Saaty (2003), metode algoritma ANP sebagai bentuk pengembangan dari algoritma AHP digunakan untuk mengatasi faktorfaktor yang tidak dapat mendukung dalam pengambilan keputusan untuk permasalahan yang kompleks pada algortima AHP. Adapun tahapan penyusunan AHP sebagai berikut:

1. Menyusun struktur masalah dan mengembangkan model keterkaitan, melakukan penentuan sasaran atau tujuan yang diinginkan, menentukan kriteria mengacu pada kriteria kontrol dan menentukan alternatif pilihan. Jika terdapat elemen - elemen yang memiliki kualitas etara maka dikelompokkan ke dalam suatu komponen yang sama.

2. Membentuk matriks perbandingan berpasangan. ANP mengasumsikan bahwa pengambil keputusan harus membuat perbandingan kepentingan antara seluruh elemen untuk setiap level dalam bentuk berpasangan. Perbandingan tersebut ditransformasi ke dalam bentuk matriks A. Nilai aij merepresentasikan nilai kepentingan relative dari elemen pada baris ke-i terhadap elemen pada kolom ke-j. misalnya aij =wi $/$ wj. Jika ada $n$ elemen yang dibandingkan maka matriks perbandingan $\mathrm{A}$ idefinisikan sebagai :

$$
\begin{aligned}
\mathrm{A} & =\left[\begin{array}{ccc}
\frac{w 1}{w 1} & \frac{w 1}{w 2} \cdots & \frac{w 1}{w n} \\
w 2 & w 2 & \frac{w 2}{w 1} \\
\frac{w 2}{w n} & \vdots & \frac{1}{w} \\
\frac{w n}{w n} & \underline{w n} & \underline{w n}
\end{array}\right] \\
& =\left[\begin{array}{ccc}
1 & \mathrm{a}_{12} & a_{1 n} \\
\mathrm{a}_{21} & 1 & a_{2 n} \\
a_{n 1} & a_{n 2} & 1
\end{array}\right]
\end{aligned}
$$

3. Menghitung bobot elemen. Jika perbandingan berpasangan telah lengkap, vector prioritas $\mathrm{W}$ yang disebut sebagai eigenvector dihitung dengan rumus:

$$
\mathrm{A} . \mathrm{W}=\lambda \text { maks. } \mathrm{W}
$$

A adalah matriks perbandingan berpasangan dan $\lambda$ maks adalah eigen value terbesar dari A. Eigen vector merupakan bobot prioritas suatu matriks yang kemudian digunakan dalam penyusunan supermatriks.

4. Menghitung rasio konsistensi. Rasio konsistensi tersebut harus $10 \%$ atau kurang. Jika nilainya lebih dari 10\%, maka penilaian data keputusan harus diperbaiki. Dalam prakteknya, konsistensi tersebut tidak mungkin didapat. Pada matriks konsistensi, secara praktis $\lambda$ maks $=\mathrm{n}$, sedangkan pada matriks tidak setiap variasi dari wijakan membawa perubahan pada nilai $\lambda$ maks. Deviasi $\lambda$ maks dari $n$ merupakan suatu parameter Consistency Index (CI) sebagai berikut:

$$
C I=\frac{\lambda_{\max }-n}{n-1}
$$


Keterangan: CI (Consistency Index); $\lambda$ maks (nilai eigen terbesar); $\mathrm{n}$ (jumlah elemen yang dibandingkan).

5. Nilai CI tidak akan berarti apabila terdapat standar untuk menyatakan apakah CI menunjukkan matriks yang konsisten. Saaty (2008) memberikan patokan dengan melakukan perbandingan secara acak atas lima ratus buah sampel. Saaty berpendapat bahwa suatu matriks yang dihasilkan dari perbandingan yang dilakukan secara acak merupakan suatu matriks yang mutlak tidak konsisten. Dari matriks acak tersebut didapatkan juga nilai Consistency Index, yang disebut Random Index (RI). Dengan membandingkan CI dan RI maka didapatkan patokan untuk menentukan tingkat konsistensi suatu matriks, yang disebut Consistency Ratio (CR), dengan rumus sebagai berikut:

\section{$\mathbf{C R}=\mathbf{C I} / \mathbf{R I}$}

Keterangan: CR (Consistency Ratio); CI (Consistency Index); RI (Random Index). Nilai RI merupakan nilai random index yang dikeluarkan oleh Oarkridge Laboratory.

6. Membuat supermatriks merupakan hasil vektor prioritas dari perbandingan berpasangan antar cluster, kriteria dan alternatif. Supermatriks terdiri dari tiga tahapan, yaitu supermatriks tidak tertimbang (Unweighted Supermatrix), supermatriks tertimbang (Weighted Supermatrix) dan supermatriks limit (Limitting Supermatrix).

a. Tahap Unweighted Supermatrix. Unweighted Supermatrix dibuat berdasarkan perbandingan berpasangan antar cluster, kriteria dan alternatif dengan cara memasukkan vector prioritas (eigen vector) kolom ke dalam matriks yang sesuai dengan selnya.

b. Tahap Weighted Supermatrix. Weighted Supermatrix diperoleh dengan cara mengalihkan semua elemen pada unweighted supermatrix dengan nilai yang terdapat dalam matriks cluster yang sesuai sehingga setiap kolom memiliki jumlah satu.

c. Tahap Limmiting Supermatrix. Selanjutnya, untuk memeroleh limiting supermatrix, weighted supermatrix dinaikkan bobotnya. Menaikkan bobot weighted supermatrix dilakukan dengan cara mengalikan supermatriks tersebut dengan dirinya sendiri sampai beberapa kali. Ketika bobot pada setiap kolom memiliki nilai yang sama, maka limitting supermatrix sudah didapatkan.
7. Rangking alternatif

a. Bobot raw merupakan nilai eigen vector dari normalisasi limitting supermatriks.

b. Bobot normal yang didapatkan dari nilai bobot raw dibagi dengan jumlah total dari bobot raw.

c. Bobot ideal dimana nilai ideal adalah nilai hasil bagi kolom (kolom nilai normal) dengan nilai terbesar pada kolom normal.

\section{HASIL}

Rancangan kerangka ANP yang telah dibuat dalam bentuk cluster siap olah dengan piranti lunak Super Decision V2.10 dan dapat dilihat pada Gambar 2. Rancangan ini dibuat berdasarkan ANP yang telah disusun, kemudian dikembangkan dalam bentuk kuesioner ANP dan diisi berdasarkan justifikasi pakar.

Sintesis model secara keseluruhan berdasarkan matriks perbandingan berpasangan (pairwised comparisons) yang diperoleh melalui pengolahan data yang dilakukan satu persatu oleh masing-masing responden pakar dengan bantuan piranti lunak (software) Super Decision V2.10. Olahan piranti lunak tersebut menghasilkan sintesis model secara keseluruhan alternatif strategi dan supermatriks yang berguna untuk menampilkan urutan prioritas cluster-cluster terpenting dari faktorfaktor terkait. Kemudian hasil keluaran (output) super decisions hasil sintesis semua model (whole model) dan super matriks masing-masing pakar diolah secara rata-rata geometriknya (geomean) untuk menghasilkan model akhirnya seluruh pendapat pakar.

Urutan ranking/prioritas dari masing-masing cluster diperoleh berdasarkan geometrik pendapat seluruh pakar. Analisis per cluster menggunakan nilai limiting. Hasil sintesis dan prioritas secara keseluruhan dan per cluster berdasarkan pendapat gabungan responden dapat dilihat pada Tabel 1.

Tabel 1 menunjukkan bahwa strategi yang akan diterapkan terdiri dari tujuh cluster yaitu industri pendukung, industri inti, rekayasa spesifikasi dan desain, studi kelayakan, penelitan dan pengembangan, faktor kondisi, dan pemerintah. Apabila dilihat secara rinci berdasarkan pengaruh masing-masing cluster, tentunya bobot dan prioritas masing-masing alternatif strategi akan berbeda tergantung sudut pandang dan dimana faktor yang berpengaruh. 


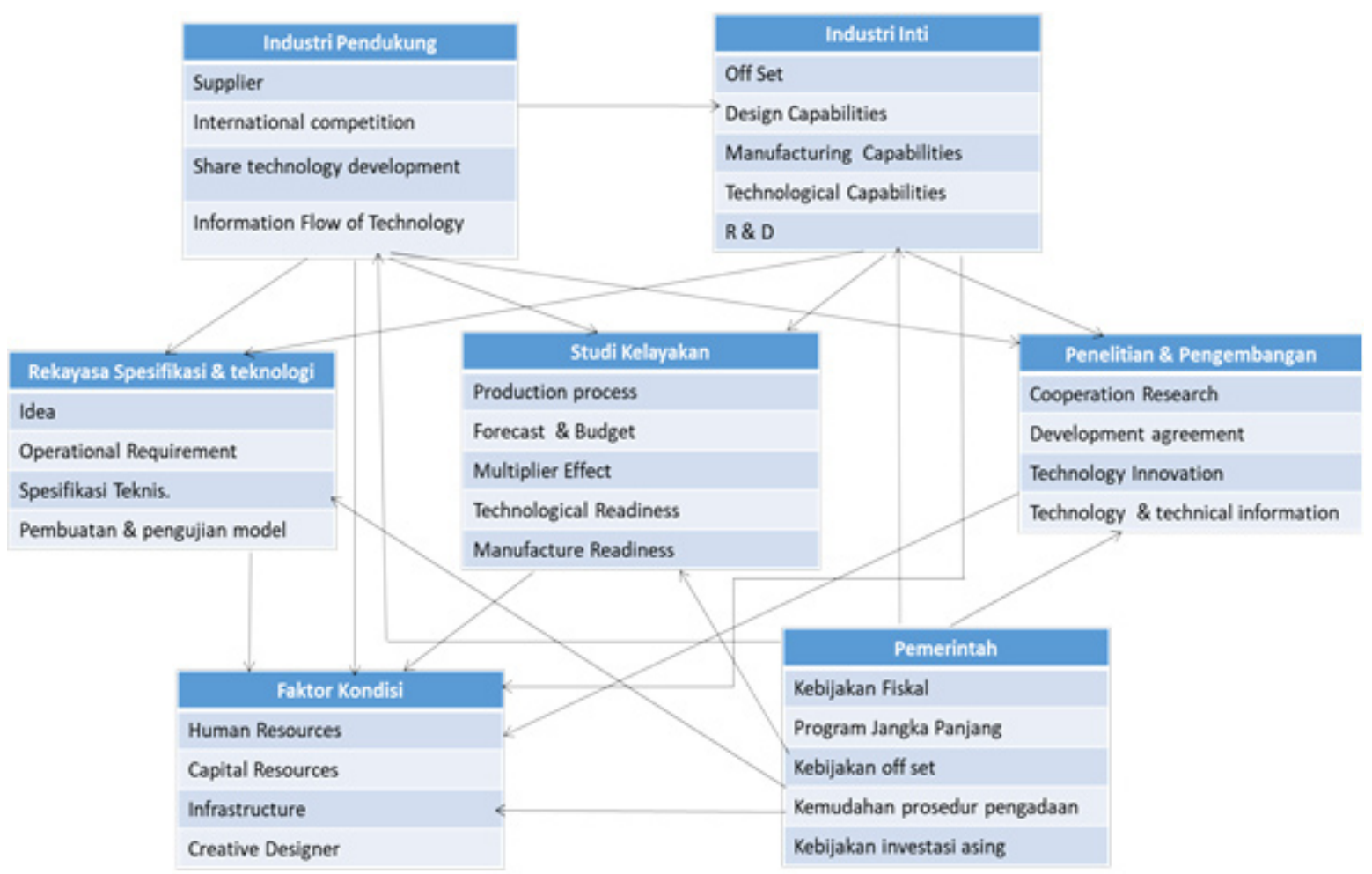

Gambar 2. Rancangan kerangka ANP peningkatan daya saing industri maritim dengan Super Decision V2.10

Tabel 1. Urutan faktor prioritas

\begin{tabular}{lcccc}
\hline Name & Normalized By luster & Limiting & Ranking All & Ranking per cluster \\
\hline IP1 Supplier & 0,227171 & 0,001331 & 25 & 3 \\
IP2 International Competition & 0,186618 & 0,001093 & 26 & 4 \\
IP3 Share Technology Development & 0,240549 & 0,001409 & 23 & 1 \\
IP4 Information Flow of Technology & 0,231332 & 0,001355 & 24 & 2 \\
II1 Off Set & 0,122337 & 0,002026 & 22 & 5 \\
II2 Design Capabilities & 0,183416 & 0,003038 & 20 & 3 \\
II3 Manufacturing Capabilities & 0,206731 & 0,003424 & 19 & 2 \\
II4 Technological Capabilities & 0,282156 & 0,004673 & 18 & 1 \\
II5 R\&D & 0,133061 & 0,002204 & 21 & 4 \\
SD1 Idea & 0,282033 & 0,012157 & 6 & 1 \\
SD2 Operational Requirement & 0,24518 & 0,010568 & 10 & 2 \\
SD3 Spec.Teknis & 0,225498 & 0,00972 & 11 & 3 \\
SD4 Pembuatan dan Pengujian Model & 0,161183 & 0,006947 & 14 & 4 \\
SK1 Production process & 0,139514 & 0,006013 & 15 & 3 \\
SK2 Forecast \& budget & 0,11697 & 0,005042 & 17 & 5 \\
SK3 Multiplier effect & 0,132568 & 0,005714 & 16 & 4 \\
SK4 Technological readiness & 0,305199 & 0,013155 & 5 & 1 \\
SK5 Manufacture readiness & 0,252841 & 0,010898 & 9 & 2 \\
PP1 Cooperation Research & 0,202113 & 0,008712 & 12 & 3 \\
PP2 Development Agreement & 0,182719 & 0,007876 & 13 & 4 \\
PP3 Technological Innovation & 0,272721 & 0,011755 & 7 & 1 \\
PP4 Technology and Technical Info & 0,26958 & 0,01162 & 8 & 2 \\
FK1 Human Resouces & 0,287778 & 0,241127 & 1 & 3 \\
FK2 Capital Resources & 0,205344 & 0,172056 & 3 & \\
\hline & & & & 2 \\
& & & 2 \\
\end{tabular}


Tabel 1. Urutan faktor prioritas (Lanjutan)

\begin{tabular}{lcccc}
\hline Name & Normalized By luster & Limiting & Ranking All & Ranking per cluster \\
\hline FK3 Infrastructure & 0,204014 & 0,170941 & 4 & 4 \\
FK4 Creative Designer & 0,233739 & 0,195847 & 2 & 2 \\
PE1 Kebijakan Fiskal & 0,144462 & 0,000393 & 29 & 3 \\
PE2 Program Jangka Panjang & 0,378138 & 0,001028 & 27 & 1 \\
PE3 Kebijakan off set & 0,237222 & 0,000645 & 28 & 2 \\
PE4 Kemudahan prosedur pengadaan & 0,087834 & 0,000239 & 30 & 4 \\
PE5 Kebijakan investasi asing & 0,074872 & 0,000204 & 31 & 5 \\
\hline
\end{tabular}

Berdasarkan industri pendukung yang merujuk pada Gambar 3 prioritas utama strategi di antaranya adalah Share Technology Development (IP3) yang kemudian disusul oleh Information Flow of Technology (IP4), Supplier (IP1), dan International Competition (IP2). Hidayat et al. (2015) dalam penelitiannya juga menyatakan bahwa penguasaan terhadap pasar domestik, pemfokuskan pengembangan produk tertentu dan integrasi antar pelaku pasar merupakan strategi untuk peningkatan daya saing industri kapal berkelanjutan. Jika penguasaan terhadap pasar domestik sudah diperoleh maka industri kapal dapat berdaya saing pada international competition.

Gambar 4 menunjukkan bahwa cluster industri inti prioritas utamanya yaitu Technological Capabilities (II4) kemudian prioritas selanjutnya secara berturutturut yaitu Manufacturing Capabilities (II3), Design Capabilities (II2), R\&D (II5), dan terakhir adalah OffSet (II1). Sementara berdasarkan penelitian Ma'ruf (2014) standarisasi tipe dan ukuran kapal pelayaran lokal, revitalisasi fasilitas dan peralatan galangan berbasis teknologi maju, pengembangan kemampuan inovasi dan rancang bangun kapal, dan pengembangan industri komponen kapal di dalam negeri merupakan strategi untuk daya saing industri kapal nasional. Menurut Lungari (2017), Teknologi merupakan penentu daya saing suatu galangan kapal, yang terdiri dari komponen permesinan, metode, dan komponen humanware.

Rekayasa spesifikasi dan desain yang ditunjukkan pada Gambar 5 memiliki prioritas utama yaitu Idea (SD1) kemudian disusul oleh Operational Requirement (SD2), Spesifikasi Teknis (SD3), dan Pembuatan dan Pengujian Model (SD4).
Pada cluster studi kelayakan yang merujuk pada Gambar 6 dapat dilihat bahwa prioritas utama strategi yang dipilih adalah Technological Readiness (SK4) kemudian prioritas selanjutnya secara berturut-turut adalah Manufacture Readiness (SK5), Production Process (SK1), Multiplier Effect (SK3), dan Forecast \& budget (SK2). Virliantarto et al. (2017) dan Lungari (2017) mengatakan pengukuran kesiapan komponen teknologi (Technological Readiness) dirasa penting dalam perkembangan industri kapal karena dapat melihat bagaimana kesiapan kapal dalam melakukan pembangunan secara massal.

Selanjutnya, pada cluster Penelitian dan pengembangan merujuk pada Gambar 7 dapat dilihat bahwa strategi yang menjadi prioritasnya adalah aspek Technological Innovation (PP3), disusul dengan aspek Technology and technical info (PP4), Cooperation Research (PP1), dan Development Agreement (PP2). Pengembangan dan inovasi teknologi (Technological Innovation) memiliki peran penting untuk daya saing industri kapal. Ma'ruf (2014) strategi pembangunan sektor maritim yang terpadu dan inovasi teknologi rancang bangun kapal berorientasi produktivitas, sehingga industri galangan kapal nasional mampu berdaya saing dengan cepat.

Pada cluster Faktor Kondisi, aspek Human resources (FK1) menjadi prioritas utama yang dapat dilihat pada Gambar 8 dalam melakukan strategi peningkatan daya saing, kemudian prioritas selanjutnya secara berturut-turut adalah aspek Capital Resources (FK2), Infrastructure (FK3), dan Creative Designer (FK4). Ma'ruf et al. (2006) mengatakan juga bahwa human resource merupakan salah satu faktor internal yang berpengaruh terhadap daya saing galangan kapal. 


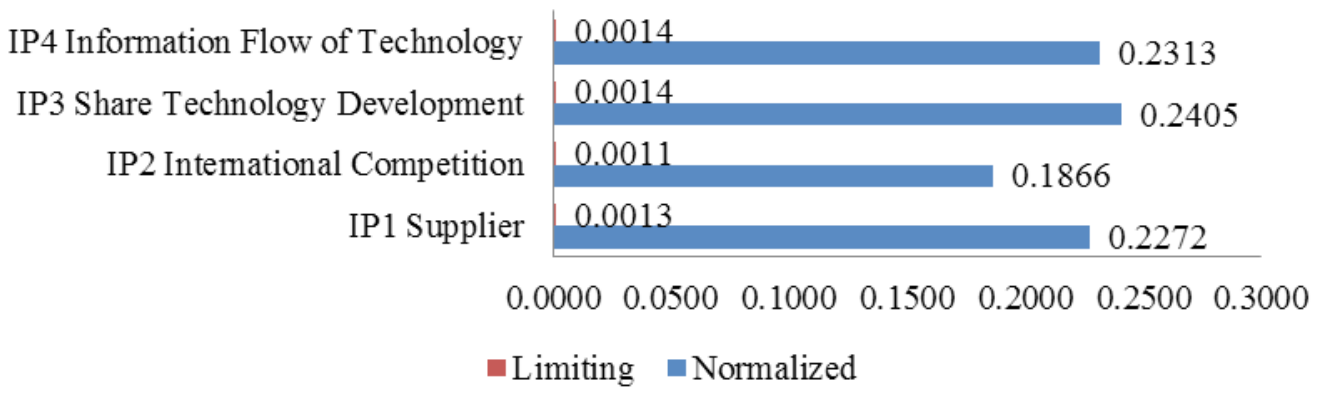

Gambar 3. Nilai normalized dan limitingcluster Industri Pendukung

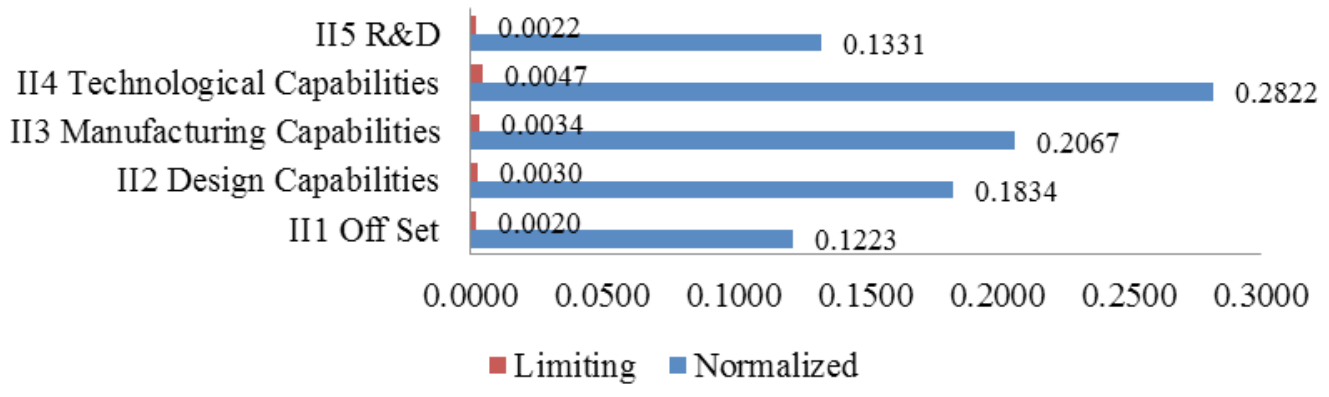

Gambar 4. Nilai normalized dan limitingcluster Industri Inti

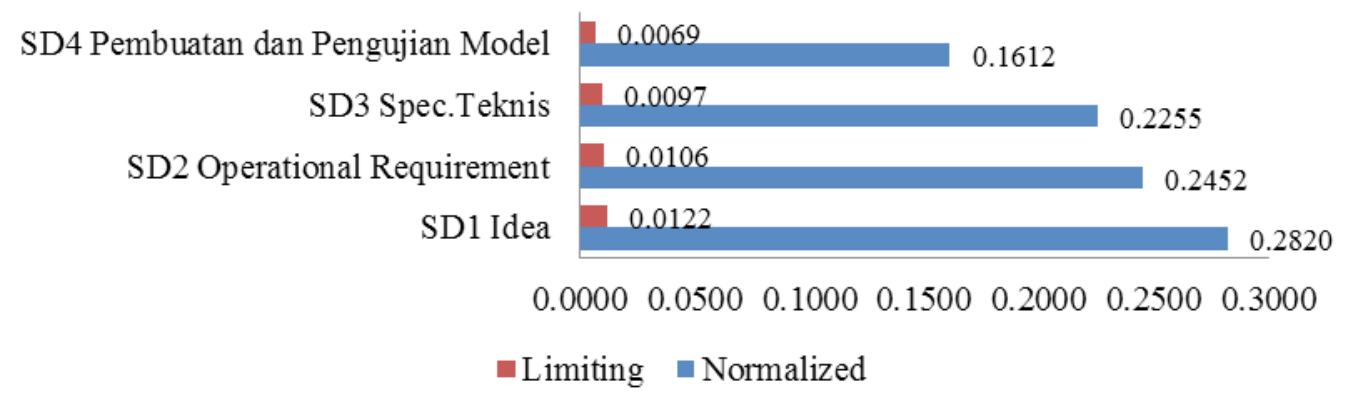

Gambar 5. Nilai normalized dan limitingcluster Rekayasa Spesifikasi dan Desain

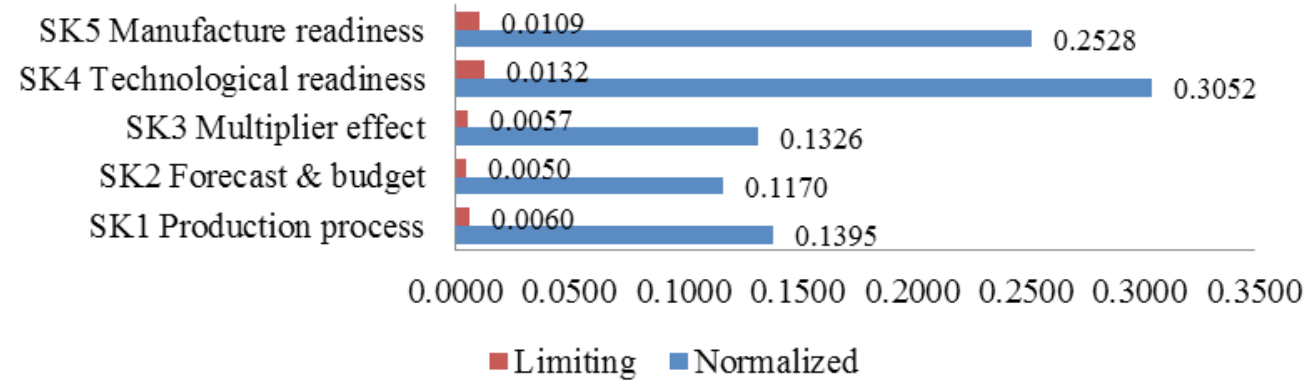

Gambar 6. Nilai normalized dan limitingcluster Studi Kelayakan 


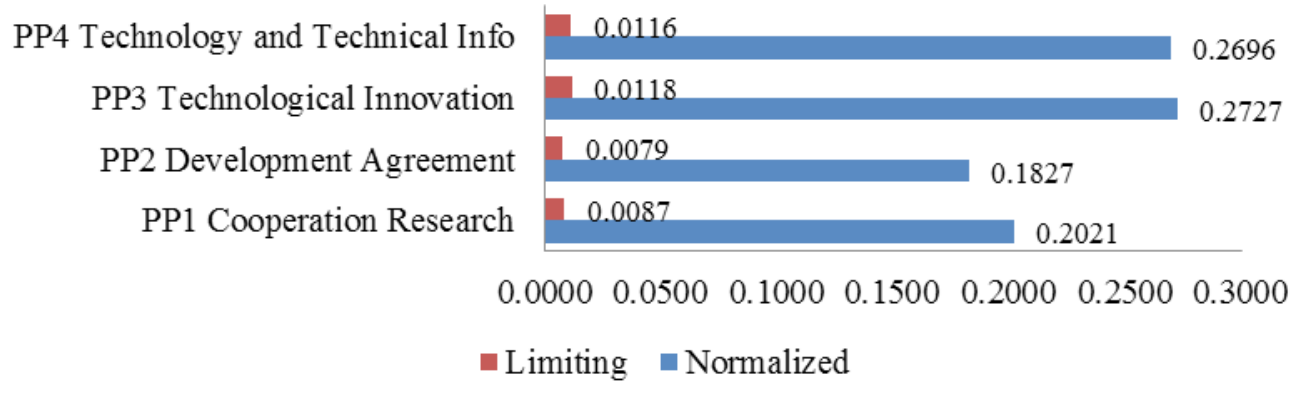

Gambar 7. Nilai normalized dan limitingcluster Penelitian \& Pengembangan

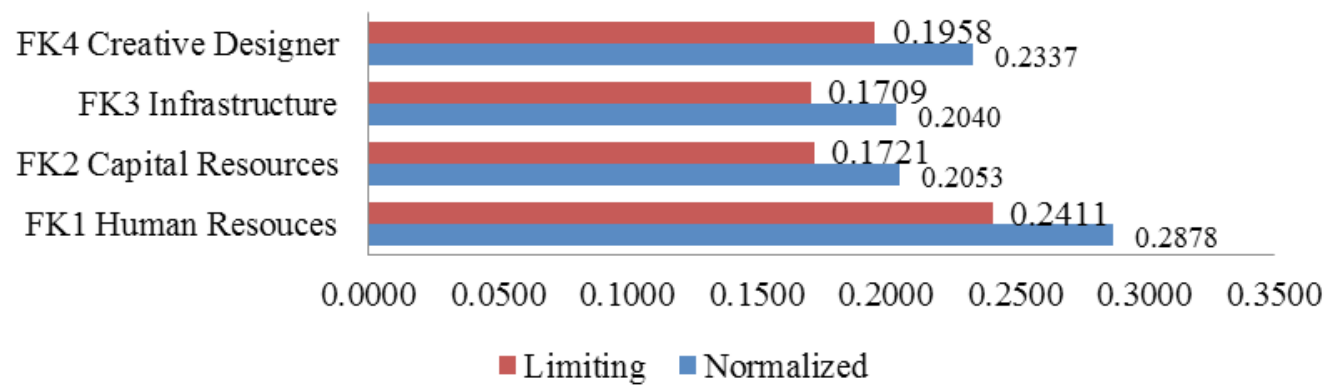

Gambar 8. Nilai normalized dan limitingcluster Faktor Kondisi

Untuk cluster terakhir merujuk pada Gambar 9, yaitu Cluster Pemerintah dengan strategi prioritas utamanya adalah Program Jangka Panjang (PE2), kemudian Kebijakan Off Set (PE3), Kebijakan Fiskal (PE1), Kemudahan Prosedur Pengadaan (PE4), dan Kebijakan Investasi Asing (PE5). Terkait dengan kebijakan dan regulasi pemerintah Idrus et al. (2018) dalam penelitiannya juga mengemukakan bahwa kerjasama industri perkapalan dan industri pendukung perkapalan memerlukan perubahan regulasi terkait pengelolaan manajemen industri perkapalan. Perubahan tersebut untuk mengatasi permasalahan yang dihadapi oleh pemerintah dan produsen industri perkapalan. Dalam Undang-undang Nomor 16 Tahun 2012 Tentang Industri Pertahanan ditekankan pemanfaatan industri nasional dalam pemenuhan Alutsista sehingga memerlukan pengelolaan menajemen industri pertahanan dengan industri pendukung lainnya.

Urutan prioritas hasil ANP berdasarkan hasil justifikasi masing-masing pakar secara keseluruhan juga dilakukan pengujian. Pengujian dilakukan dengan menggunakan analisis Rater Agreement dengan bantuan piranti lunak statistika "Minitab" dengan terlebih dahulu mengurutkan (ranking) masing-masing bobot atribut per pakar yang dihasilkan oleh ANP.
Apabila hasil analisis dengan ANP berdasarkan justifikasi pakar perlu dihipotesiskan dalam penelitian ini dapat maka hasil hipotesis dapat di lihat pada Tabel 2. Berdasarkan hipotesis awal, semua hipotesis terbukti karena nilai tertinggi dan prioritas masing-masing klister terbukti.

\section{Analisis Rater Agreement Hasil ANP}

Metode ANP adalah metode pengambilan keputusan menggunakan judgment para pakar melalui kuesioner perbandingan berpasangan (pairwised comparisons). Dengan perangkat ini para pakar diberikan kemudahan untuk fokus dalam pengambilan keputusan. Akurasi tingkat kesepakatan para responden terhadap penentuan prioritas Analisis Rater Agreement menunjukkan nilai koefisien Kendall's $W$, yaitu nilai normalisasi dari Friedman Statistic. Rentang skala nilai koefisien Kendall's $W$ adalah antara nol sampai dengan satu, dengan pengertian bahwa nilai nol berarti tidak ada kesepakatan dan nilai satu yang berarti kesepakatan sempurna.

Berdasarkan hasil analisis Kendall's dapat dikatakan signifikan apabila nilai $\mathrm{P} \leq 10 \%$ dan dapat dinyatakan bahwa seluruh responden pakar memiliki kesepakan yang tinggi ditunjukkan dengan nilai koefisien Kendall's $>0,38$. Berdasarkan Tabel 3 diketahui 
bahwa secara relatif seluruh pakar menyatakan sepakat terhadap keseluruhan cluster. Namun hanya pada cluster studi kelayakan responden memiliki kesepakatan yang tinggi sedangkan pada cluster yang lainnya responden menunjukkan kesepakatannya relatif rendah. Namun demikian hasil geometric mean dapat mewakili prioritas yang terbaik secara keseluruhan. Hasil analisis ANP menghasilkan bahwa strategi yang akan diterapkan terdiri dari tujuh cluster yaitu industri pendukung, industri inti, rekayasa spesifikasi dan desain, studi kelayakan, penelitan dan pengembangan, faktor kondisi, dan pemerintah.

Pada cluster industri pendukung strategi yang menjadi prioritas adalah share technology development, untuk meningkatkan kemampuan perusahaan dalam cluster maka perlu interaksi yang intens agar semua mengetahui teknologi yang sedang dikembangkan. Ini dapat dikembangkan melalui jaringan triple helix antara pemerintah universitas dan industri ( $\mathrm{Li}, 2019$ ).

Jika dilihat dari cluster industri inti maka strategi yang menjadi prioritas adalah technological capabilities, berupa kemampuan mengimplementasikan hasil riset pengembangan menjadi produk baru, seperti pada penelitian Tulyakova dan Irina (2017) di industri shipbuilding Rusia penjualan kapal sipil lebih banyak tetapi nilainya $22 \%$ dari penjuan sementara penjualan kapal perang nilainya lebih banyak tetapi nilainya $82 \%$ dari total penjualan, kapal perang yang menggunakan teknologi yang komplek membutuhkan kemampuan teknologi untuk menghasilkan kapal perang yang canggih dan baru serta dibutuhkan pasar walaupun harganya mahal.

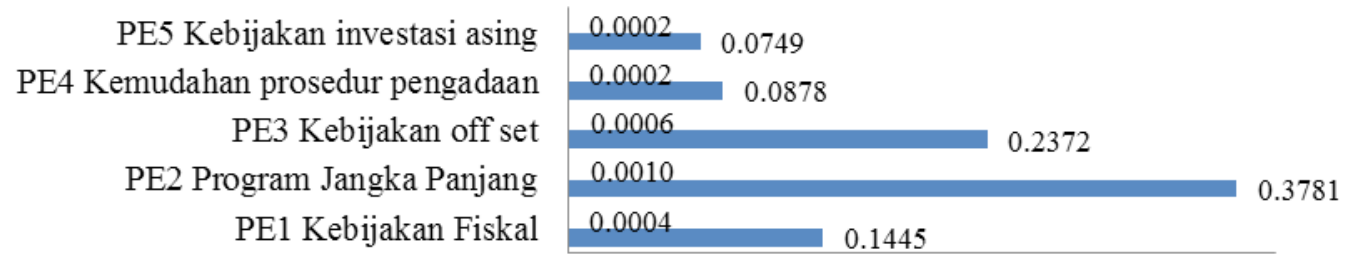

$0.000 œ .050 œ .100 œ .150 œ .200 œ .250 œ .300 œ .350 œ .4000$

- Limiting Normalized

Gambar 9. Nilai normalized dan limitingcluster Pemerintah

Tabel 2. Hipotesis penelitian

\begin{tabular}{lll}
\hline Klaster & Ranking Klaster & Hipotesa \\
\hline Industri Inti & Technology & Technology Capabilites mendukung peningkatan daya saing industri \\
& Capabilites & perkapalan. \\
Penelitian dan & Technological & Program Research and Development mendukung kemampuan Technological \\
Pengembangan & Innovation & Innovation. \\
Pemerintah & Program Jangka & Diperlukan program jangka panjang pembangunan kapal untuk meningkatkan \\
& Panjang & kemampuan industri. \\
Faktor Kondisi & Human Resources & Kualitas sumber daya manusia menentukan daya saing industri perkapalan \\
\hline
\end{tabular}

**Note: Semua hipotesa terbukti karena pada masing-masing klaster rangking tertinggi sesuai hipotesa.

Tabel 3. Indeks keakuratan koefisien Kendall's all cluster

\begin{tabular}{lccccc}
\hline Atribut/ Cluster & Koefisien Kendall's & Chi-Sq & DF & P & Keterangan \\
\hline All cluster & 0,575 & 224,177 & 30 & 0,0000 & Signifikan pada alpha 1\% \\
Industri Pendukung & 0,231 & 9 & 3 & 0,0293 & Signifikan pada alpha $1 \%$ \\
Industri Inti & 0,017 & 0,862 & 4 & 0,9300 & Tidak signifikan \\
Rekayasa Spesifikasi dan Design & 0,309 & 12,046 & 3 & 0,0072 & Signifikan pada alpha $1 \%$ \\
Studi Kelayakan & 0,467 & 24,308 & 4 & 0,0001 & Signifikan pada alpha $1 \%$ \\
Penelitian \& Pengembangan & 0,212 & 8,262 & 3 & 0,0409 & Signifikan pada alpha $1 \%$ \\
Faktor Kondisi & 0,082 & 3,185 & 3 & 0,3640 & Tidak signifikan \\
Pemerintah & 0,083 & 43,139 & 4 & 0,0000 & Signifikan pada alpha $1 \%$ \\
\hline
\end{tabular}


Pada rekayasa spesifikasi dan desain memiliki prioritas utama, yaitu idea yang merupakan inovasi berpikir peneliti berdasarkan perkembangan lingkungan. Sementara itu, menurut Park (2015) daya saing industri dapat ditingkatkan dengan model pembuatan kapal dengan desain standar untuk mengurangi biaya pengembangan produksi. Ide bisa dikembangkan melalui riset penelitian dan pengembangan untuk menghasilkan teknologi yang baru, dari segi kualitas, kemampuan maupun desain.

Pada cluster studi kelayakan, prioritas utamanya adalah technological readiness, yaitu kesiapan teknologi untuk dipasarkan setelah melalui pengujian dilingkungan yang sebenarnya. Analisis technological readiness diperlukan karena investasi yang digunakan cukup besar (Nujen, 2019) dalam memproduksi teknologi sehingga diperlukan keyakinan kesiapan teknologi tersebut sebelum di produksi untuk pasar. Markus dan Wang (2020) menjelaskan pentingnya kesiapan teknologi agar customer dapat menggunakan teknologi tersebut dengan aman.

Cluster penelitian dan pengembangan, strategi yang menjadi prioritasnya adalah aspek technological innovation untuk menghasilkan produk yang berkualitas, efisien dan baru. Menurut Hong (2017) technology innovation terjadi di industri dimulai dari new technical idea kemudian melalui proses inkubasi dengan mentransfer teknologi tersebut ke industri yang selanjutnya diproduksi untuk pasar.

Pada cluster faktor kondisi aspek human resources sebagai prioritas strategi dalam mengembangkan industri. Dalam proses pengembangan teknologi berawal dari pembangunan ide baru kemudian dilaksanakan riset pengembangan di lembaga penelitian dan universitas yang semuanya membutuhkan sumber daya manusia (Hong, 2017) berkualitas untuk menghasilkan inovasi teknologi. Proses industrialisasi inovasi melalui transformasi sains dan teknologi ke teknologi baru dalam industri industri membutuhkan sumberdaya manusia yang menguasai science and technology.

Cluster pemerintah yang menjadi prioritas utamanya adalah program jangka panjang, industri membutuhkan dukungan pemerintah dalam bentuk program pesanan kapal jangka panjang agar industri dapat mengembangkan kemampuannya. Pada penelitian DuBois (2016); Cao (2014) menyatakan peran pemerintah dalam mendukung industri berupa pamberian subsidi dan bantuan pajak. Sementara itu, Çera dan Gentjan (2019) mengatakan faktor yang memengaruhi kepercayaan pengusaha kepada pemerintah adalah korupsi,pengadilan, peraturan pajak dan ketenagakerjaan.

Berdasarkan hasil analisis rater agreement diketahui bahwa secara relatif seluruh pakar menyatakan sepakat terhadap keseluruhan cluster. Namun, hanya pada cluster studi kelayakan responden memiliki kesepakatan yang tinggi. Pada cluster yang lainnya responden menunjukkan kesepakatannya relatif rendah.

\section{Implikasi Manajerial}

Untuk meningkatkan daya saing industri perkapalan, pemerintah diharapkan membantu industri terutama berupa program jangka panjang maupun subsidi kepada industri. Lou (2020) mengatakan subsidi pemerintah Amerika semakin meningkatkan daya saing ekspor produk-produk teknologi tinggi domestiknya. Kapal digunakan dalam waktu tertentu sepanjang daur hidupnya (umumnya 30-40 tahun) sehingga kebutuhan kapal dalam jangka panjang dapat diprediksi jumlah yang dibutuhkan. Industri perkapalan akan bertahan hidup jika ada kepastian pesanan kapal dalam jangka panjang, karena industri perkapalan membutuhkan modal besar dan menggunakan tenaga kerja yang cukup banyak. Sumber daya manusia juga harus di tingkatkan kemampuannya melalui pendidikan dan pelatihan. Industri, pemerintah dan lembaga penelitian maupun universitas harus bekerja sama untuk meningkatkan daya saing industri melalui program penelitian dan pengembangan teknologi. Etzkowitz (2013) dalam konteks teori Triple Helix, inovasi teknologi adalah hasil dari praktik yang baik dalam interaksi antara tiga bidang kelembagaan: universitas-industri pemerintahan. Untuk memajukan industri maka perusahaan-perusahaan dalam industri perkapalan juga harus bekerja sama untuk mengembangkan teknologi. Amdam dan Bjarnar (2015) mengatakan bahwa kombinasi persaingan dan kerja sama, termasuk berbagi pengetahuan antar perusahaan, merupakan mekanisme peningkatan yang pentingdan berkontribusi pada daya saing cluster. 


\section{KESIMPULAN DAN SARAN}

\section{Kesimpulan}

Hasil analisis ANP maka dapat disimpulkan strategi yang akan diterapkan terdiri dari tujuh cluster yaitu industri pendukung, industri inti, rekayasa spesifikasi dan desain, studi kelayakan, penelitan dan pengembangan, faktor kondisi, dan pemerintah. Jika dilihat dari cluster industri inti, maka strategi yang menjadi prioritas adalah technological capabilities. Menurut Bojic (2020), teknologi adalah sumber utama keunggulan kompetitif. Pada cluster industri pendukung strategi prioritas utamanya adalah share technology development. Connell (2013) menyampaikan bahwa berbagi pengetahuan untuk memediasi hubungan antara pasar dan keunggulan kompetitif. Pada cluster rekayasa spesifikasi dan desain strategi prioritas utamanya, yaitu idea. Pada cluster studi kelayakan prioritas utamanya adalah technological readiness.Pada cluster penelitian dan pengembangan strategi yang menjadi prioritasnya adalah aspek technological innovation. Menurut Reve (2015), daya saing dipasar internasional berdasarkan teknologi yang canggih dan model bisnis yang efektif. Pada cluster faktor kondisi strategi prioritasnya adalah aspek human resource, dan pada cluster pemerintah strategi prioritas utamanya adalah program jangka panjang. Berdasarkan hasil analisis rater agreement diketahui bahwa secara relatifseluruh pakar menyatakan sepakat terhadap keseluruhan cluster. Namun, pada cluster studi kelayakan responden memiliki kesepakatan yang tinggi, sedangkan pada cluster yang lainnya responden menunjukkan kesepakatannya relatif rendah.

\section{Saran}

Dalam penelitian ini masih terdapat keterbatasan peneliti seperti faktor-faktor yang digunakan masih terbatas, hanya menggunakan tujuh cluster yang mewakili cluster industri, alih teknologi dan daya saing. Sementara masih banyak faktor lain yang dapat memengaruhi daya saing industri perkapalan. Demikian juga subelemen cluster, elemen yang digunakan masih terbatas sementara masih banyak subelemen lain yang bisa digunakan untuk lebih baik dalam memilih komponen strategi peningkatan daya saing industri perkapalan.

\section{DAFTAR PUSTAKA}

[Kemenperin] Kementerian Perindustrian. 2017. Kembangkan Produksi Kapal. https:// kemenperin.go.id/artikel/17339/KembangkanProduksi-Kapal. [18 Mar 2020].

Amdam RP, Bjarnar O. 2015. Globalization and the development of industrial clusters: Comparing two norwegian clusters, 1900-2010. Business History Review 89(4): 693-716.

Bojic B. 2020. Us Technological Transfer Legal Considerations With Special Emphasis On Bayh-dole Act And Federal Technology Transfer Act. Varazdin: Varazdin Development and Entrepreneurship Agency (VADEA).

Cao X, Liu Y, Cao C. 2014. Institutional entrepreneurs on opportunity formation and exploitation in strategic new industry: Two cases of solar energy industry development in china. International Journal of Emerging Markets 9(3): 439-458.

Çera G, Meço M, Çera E, Maloku S. 2019. The effect of institutional constraints and business network on trust in government: an institutional perspectiveAdministratie si Management Public; Bucharest Iss 33(2019): 6-19.

Čolović ZK, Beran IM, Ivona VR. 2016. The impact of clustering on the business performance of croatian SMHEs: Znanstveno-strucni casopis. Ekonomska Istrazivanja 29(1).

Connell J, Voola R. 2013. Knowledge integration and competitiveness: A longitudinal study of an industry cluster. Journal of Knowledge Management 17(2): 208-225.

Cunningham JA. 2017. A Review of Qualitative Case Methods Trends and Themes Used in Technology Transfer Research. Journal of Technology Transfer.

DuBois FL, Marcos AMP. 2016. State capitalism and clusters: The case of brazilian shipbuilding. International Journal of Emerging Markets, 11(2): 214-231.

Etzkowitz H. 2013. Hélice tríplice: universidadeindústria-governo: inovação em movimento. 1. ed. Porto Alegre: EDIPUCRS.

Fongsuwan. 2017. Cluster and R\&D Affecting the Competitive Advantage of the Mould and Die Sector in the Thai Automotive Industry al.Management and Production Engineering Review; Warsaw 8(4): 3-12.

Gajsek B, Kovac J. 2016. Key factors for the successful 
operation of clusters: The case for slovenia. Organizacija 49(2): 150-160.

Gross JN. 2012. Performance Based Internet Reward System. US Patent App 13/348:330.

Hassan A. 2015. International Technology Transfer Models: A Comparison Study, Journal of Theoretical and Applied Information Technology $78(1)$.

Hidayat T, Manfaat D, Ma'ruf B. 2015. Strategi daya saing industri galangan kapal Surabaya. Jurnal Wave 9(2): 79-84.

Hong Y, Lu Y, Zheng J. 2017. Industrialized innovation: The connection of science \& technology innovation with industrial innovation. Frontiers of Economics in China 12(3): 400-417.

Idrus MA, Rosyid DM, Supartono. 2018. Pengembangan industri perkapalan nasional untuk mendukung keamanan maritim Indonesia. Jurnal Keamanan Maritim 4(3): 71-86.

Li R, WF. 2019. University-industry-government relations of the ministry of industry and information technology (MIIT) universities: The perspective of the mutual information. PLoS One 14(2) .

Lou Y, Tian Y, Wang K. 2020. The spillover effect of US industrial subsidies on China's exports. Sustainability 12(7): 2938.

Lungari FF. 2017. Analisis kesiapan komponen teknologi (humanware) di Galangan Kapal Menengah (studi kasus PT Adihulung Sarana Segara Indonesia). Jurnal Ilmiah Tindalung 3(1): 31-35.

Ma'ruf B, Okumoto Y, Widjaja S. 2006. EnvironmentBased Strategic Management Model for Indonesia's Medium-Sized Shipyards. Journal of Ship Production 22(4): 195-202.

Ma'ruf. 2014. Aplikasi Manajemen Dan Teknologi Untuk Mendorong Daya Saing Industri Kapal Dan Industri Pelayaran Nasional.Prosiding Seminar Nasional Manajemen Teknologi XXI Program Studi MMT-ITS, Surabaya 19 Juli 2014.

Marčeta M, Bojnec Š. 2020. Drivers of global competitiveness in the european union countries in 2014 and 2017. Organizacija 53(1): 37-52.

Markus B, Wang C. 2020. Technology readiness: A meta-analysis of conceptualizations of the construct and its impact on technology usage. Journal of the Academy of Marketing Science 48(4): 649-669.

Nujen et al. 2019. Backshoring readiness. Journal of
Global Operations and Strategic Sourcing 12(1): 172-195.

Park YW, Hong P. 2015. Product architecture and product development: Case study of Korean shipbuilding firms Management of Engineering and Technology, 2015 Portland International Conference, August 2015.

Porter M. 1998. Clusters and The New Economics of Competition. Boston: Harvard Business Review.

Porter M. 2006. Competitiveness Framework Recent Learnings and New Research Priorities, Springer Science + Business Media, LLC.

Porter ME. 1980. Competitive Strategy. New York: The Free Press.

Porter ME. 1990.The competitive advantage of nation. The president and fellows harvard collage. All rights reserved.Harvard business review.

Porter ME. 1996. Competitive Advantage, Agglomeration Economies, and Regional Policy. International regional science review 19(1-2): 85-90.

Reve T, Sasson A. 2015. Theoretical and methodological advances in cluster research. Competitiveness Review 25(5): 524-539.

Saaty RW, Saaty TL. 2003. The Analytic Hierarchy Process (AHP) for Decision Making and The Analytic Network Process (ANP) for Decision Making With DependenceandFeedback. Creative decisions foundation.

Saaty TL, Vargas LG. 2006. Decision Making with The Analytic Network Process: Economic, Political, Social and Technological Applications with Benefits, Opportunities, Costs and Risks (Vol. 95). New York: Springer.

Saaty TL. 2008. Priorities Originate from Dominance and Order Topology in AHP/ANP. The fundamental scale, relative scales and when to preserve rank,[in:] W. Adamus (Ed.), The Analytic Hierarchy and Network Processes, Wydawnictwo Uniwersytetu Jagiellońskiego, Kraków.

Sarturi G et al. 2016. Competitiveness of clusters. International Journal of Emerging Markets 11(2): 190-213.

Sea Europe. 2018. Shipbuilding Market Monitoring Report. Ships \& Maritime equipment Association. No.45-October 2018.

Stichhauerova E, Zizka M, Pelloneova N. 2020. Comparison of the significance of clusters for increasing business performance. Journal of 
Competitiveness 12(3):172-189.

Tu H. 2011. Cluster Marketing Models and Strategies: The Implications Thereof in The Chinese HighTech Industry. International Journal of China Marketing 1(2): 34-44.

Tulyakova, Irina R, Gregova, E, Dengov, V. 2017. Assessment of Competitiveness of Shipbuilding Industry in Russia Alternate title: Procjena konkurentnosti brodograðevne industrije u Rusiji
Dubrovnik 64(3).

Virliantarto N, Ma'ruf B, Suastika K. 2017. Pengukuran kesiapan teknologi untuk pembangunan kapal kontainer 100 Teus dengan sistem modular di PT. PAL Indonesia. Jurnal Wave 11(1): 31-38.

Wang X, Liu J, Ma C. 2016. A research on the cluster competitiveness evaluation of the chinese automobile industry based on cuckoo-AHP. Chinese Management Studies 10(4): 746-769. 